\title{
Effect of nifedipine on serum theophylline concentrations and asthma control
}

\author{
S R SMITH, J WIGGINS, D E STABLEFORTH, C SKINNER, M J KENDALL
}

From the Department of Clinical Pharmacology and Therapeutics, Medical School, University of Birmingham, and the Department of Respiratory Medicine, East Birmingham Hospital, Birmingham

ABSTRACT The effect of adding slow release nifedipine to oral theophylline has been studied in eigh $\overrightarrow{\bar{B}}$ patients with stable but symptomatic asthma, a double blind placebo controlled crossover protocoit being used. No change in asthma control occurred during the nifedipine treatment period as assessed by serial peak flow measurements and symptom scores. Serum theophylline concentrations were significantly lower after nifedipine than after placebo $(6.8 v 9.7 \mu \mathrm{g} / \mathrm{ml})$ and in three patients were well below the therapeutic range $(<4 \mu \mathrm{g} / \mathrm{ml})$.

Although calcium antagonists reduce bronchoconstriction induced by exercise, histamine, and antigen, resting airway calibre is not altered to any great extent. ${ }^{1}$ They may, however, have a beneficial effect when combined with other treatment for asthma. Nifedipine potentiates the bronchodilator effect of inhaled salbutamol ${ }^{2}$ and intravenous terbutaline ${ }^{3}$ in acute studies in asthmatic subjects and it enhances the airways smooth muscle relaxation induced by theophylline $e^{4}$ in isolated guinea pig trachea. We have studied asthma control in a group of patients with stable but symptomatic asthma when nifedipine was added for two weeks to their usual asthma treatment, which included theophylline.

Several drugs are known to influence theophylline pharmacokinetics ${ }^{5}$ and these are important clinically in view of the narrow therapeutic range of theophylline. Nifedipine is widely used to treat angina and hypertension in asthmatic patients, in whom $\beta$ adrenoceptor antagonists are contraindicated. We have therefore evaluated the effect of nifedipine on serum theophylline concentrations.

\section{Methods}

Wc recruited 10 patients (six male, four female), with a mean age of 56 (range 49-70) years and with stable but symptomatic asthma. All gave informed consent to participation in the study, which had been

Address for reprint requests: Dr S R Smith, Department of Clinical Pharmacology and Therapeutics, Medical School, Birmingham 15 2TH.

Accepted 31 March 1987 approved by East Birmingham Hospital Researclo and Ethical Subcommittee. All subjects had shown at least $15 \%$ reversibility in $\mathrm{FEV}_{1}$ in response to inhale salbutamol and the $\mathrm{FEV}_{1} / \mathrm{FVC}$ ratio was less that $60 \%$ in all cases. None of the patients had ha庆 exacerbations of their asthma for at least one mont before entering the study. In addition to slow release theophylline twice daily ( $8 \mathrm{am}$ and $8 \mathrm{pm})$, all patient $\vec{\delta}$ were using inhaled $\beta_{2}$ agonists and inhaled corticos teroids. One patient was using a sodium cromoglycate inhaler and one was taking salbutamol spandets. AP. of these treatments were continued unchanges throughout the study. No patient was having ora corticosteroids or any other form of medication an none was known to have any medical condition apar? from asthma. One patient smoked and his con sumption of cigarettes remained constant throughou the study. No specific dietary restrictions were place on the patients, although they were asked to keep their consumption of food, including tea and coffeet as constant as possible, especially on the days the came to the clinic.

Before entry into the study the dose of slow releasi theophylline was adjusted to ensure serum concen trations of over $8 \mu \mathrm{g} / \mathrm{ml}$. Serum concentrations of the ophylline were measured six hours after the last dose of slow release theophylline (that is, at $2 \mathrm{pm}$ ) at eace of the four clinic attendances, as described below This is likely to represent a near peak concentration.? An enzyme mediated immunoassay (Emit, Syv: Company) was used. Assay batches contained qualit control samples and the between batch coefficient of variation of the assay was $6 \cdot 2 \%$. The addition of aD excess of nifedipine $(100 \mathrm{ng} / \mathrm{ml})$ to samples of serup 
containing theophylline did not influence scrum theophylline measurements.

Once satisfactory serum theophylline concentrations had been achieved, patients were asked to record symptoms and the best achievable peak expiratory flow (PEF) each day at $8 \mathrm{am}, 12$ noon, $6 \mathrm{pm}$, and $10 \mathrm{pm}$, before they used their bronchodilator inhaler. Symptoms included perceived severity of asthma, degree of dyspnoea, cough, and disturbance of sleep duc to asthma, each being assessed on a $0-10$ scale (that is, no symptoms $=0$, very severe symptoms $=10$ ). No change was made to their usual treatment during the first week, which served as a "practice" period. At the end of the week any problems with recordings were resolved and blood was taken for measurement of serum theophylline concentrations. These were found to be stable and within the therapeutic range in all 10 patients. Subjects were started on slow release nifedipine $20 \mathrm{mg}$ twice daily or an identical placebo tablet twice daily in addition to their usual treatment in a randomised double blind fashion. Measurements of PEF and symptom recordings were continued for a further two weeks, after which further blood was taken for serum theophylline assay. Subjects who had received nifedipine were changed to placebo and vice versa. Recordings were continued for another two weeks, at the end of which a final serum theophylline measurement was made.

Compliance with treatment was checked by tablet counts at the end of each of the two treatment periods.

Statistical comparisons were made by means of Student's $t$ test.

\section{Results}

Two men (one from each limb of the study) had to withdraw because of troublesome headache, which developed within 24 hours of starting nifedipine. The remaining cight subjects tolerated the treatment without side effects.

There was no significant difference in mean PEF measurements or combined symptom scores between the placebo and the nifedipine period (table). The combined symptom score represents the sum of the

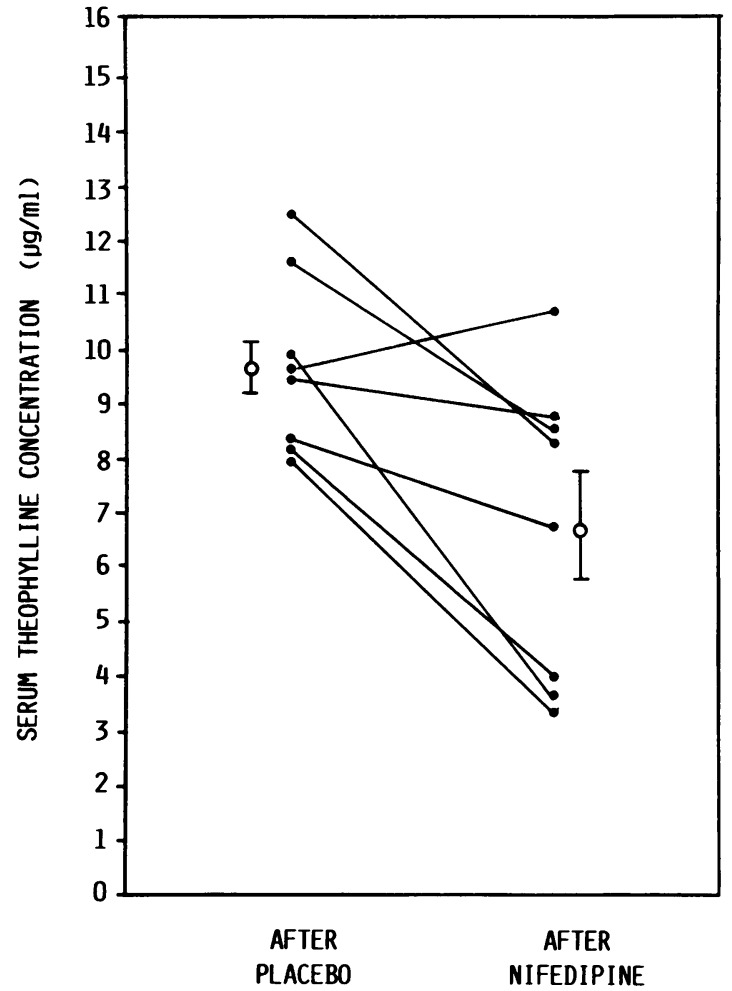

Serum theophylline concentrations in eight asthmatic subjects after two weeks' treatment with nifedipine and placebo (means with 1 standard error).

means of the two week periods of recordings of the four assessments of symptoms.

The mean (SEM) serum theophylline concentration was similar after two weeks' placebo to the concentration immediatcly before entry to the randomised part of the study $(9.7(0.5) \mu \mathrm{g} / \mathrm{ml}$ after placebo compared with $9.6(0.9) \mu \mathrm{g} / \mathrm{ml}$ after one week's practice). After nifedipine the mean theophylline concentration was significantly lower $(6.8(1.0) \mu \mathrm{g} / \mathrm{ml})$ than after either the placebo or the practice period ( $p<0.02$ for both comparisons; figure). In three patients serum theophylline concentrations after nifedipine were $4 \mu \mathrm{g} / \mathrm{ml}$ or less, representing falls of $64 \%, 56 \%$, and $50 \%$ from the levels seen after placebo.

Mean peak expiratory flow and combined symptom scores (with standard errors in parentheses) during placebo and nifedipine treatment periods in eight asthmatic subjects

\begin{tabular}{|c|c|c|c|c|c|}
\hline & \multicolumn{4}{|c|}{ Peak expiratory flow $\left(1 \mathrm{~min}^{-1}\right)$} & \multirow{2}{*}{$\begin{array}{l}\text { Combined } \\
\text { symptom score }\end{array}$} \\
\hline & $8 a m$ & 12 noon & $6 \mathrm{pm}$ & $10 \mathrm{pm}$ & \\
\hline $\begin{array}{l}\text { Placebo } \\
\text { Nifedipine }\end{array}$ & $\begin{array}{l}318(14) \\
326(17)\end{array}$ & $\begin{array}{l}349(18) \\
359(22)\end{array}$ & $\begin{array}{l}331(18) \\
333(22)\end{array}$ & $\begin{array}{l}303(18) \\
311(20)\end{array}$ & $\begin{array}{l}12 \cdot 3(2 \cdot 2) \\
10 \cdot 6(1 \cdot 7)\end{array}$ \\
\hline
\end{tabular}




\section{Discussion}

In this double blind placebo controlled crossover study of nifedipine treatment for two weeks there was no change in subjective or objective measurements of asthma control. The absence of any deterioration despite a fall in serum theophylline concentration while patients were taking nifedipine may reflect the stability of asthma in our patients. An alternative explanation is that the nifedipine was producing some benefit to compensate for the lower serum concentrations of theophylline. In patients with brittle asthma, who may be particularly dependent on theophylline treatment, the fall in serum theophylline concentration is potentially hazardous. Optimum serum theophylline concentrations are from 8 to $20 \mu \mathrm{g} / \mathrm{ml}^{7}{ }^{7}$ In a recent study of long term treatment with theophylline in combination with $\beta_{2}$ agonists the effect of theophylline on PEF and FEV 1 in theophylline responsive patients increased with increasing plasma concentrations. ${ }^{8}$ Concentrations of $4 \mu \mathrm{g} / \mathrm{ml}$ or below, as found in three of our patients after nifedipine, would not be expected to be of any therapeutic value.

The fall in theophylline concentrations during nifedipine administration may be explained by the results of a study in normal volunteers by Jackson and colleagues. ${ }^{9}$ They found that serum theophylline concentrations after an infusion of lysine theophylline were significantly lower in the presence of nifedipine during steady state chronic oral dosing owing to an increase in the mean volume of distribution of theophylline. Alternatively, nifedipine might alter theophylline absorption, although this would not account for the results with intravenous theophylline, ${ }^{9}$ or nifedipine might increase theophylline clearance by increasing liver blood flow. The latter is unlikely since, although nifedipine does increase liver blood flow, ${ }^{10}$ theophylline is subject to low hepatic extraction with a small first pass loss. Its clearance is more dependent on the activity of liver enzymes than on changes in liver blood flow. ${ }^{11}$

We suggest that, when nifedipine is used to treat angina or hypertension in patients with brittle asthma who are taking oral theophylline, serum theophylline concentrations should be monitored during the first? few weeks so that appropriate dose adjustments carc be made.

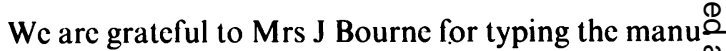
script and to Bayer UK Limited for financial supportes

\section{References}

1 Barnes PJ. Clinical studies with calcium antagonists i $\frac{\vec{p}}{\times}$ asthma. Br J Clin Pharmacol 1985;20:289-98S.

2 Lever AML, Corris PA, Gibson GJ. Nifedipine enhance the bronchodilator effect of salbutamol. Thora $\vec{b}$ 1984;39:576-8.

3 Svedmyr K, Lofdahl C-G, Svedmyr N. Nifedipinecalcium channel blocker-in asthmatic patients? Allergy 1984;39:17-22.

4 Elguindi AS, Choudry AS. The effect of nifedipine op theophylline airway smooth muscle relaxation [abstract]. Am Rev Respir Dis 1983;127:92.

5 Bukowskyj M, Nakatsu K, Munt PW. Theophyllin£ reassessed. Ann Intern Med 1984;101:63-73.

6 Rouleau MY, Stewart JH, Walker SE. Steady state phareo macokinetic and bioavailability comparison between Phyllocontin 350 and Theo-Dur 300. In: Turnero Warwick M, Levy J, eds. London: Royal Society o Medicine, 1984:129-36. (International Congress an Symposium series, No 78.)

7 Ogilvie RI. Clinical pharmacokinetics of theophyllined Clin Pharmacokinet 1978;3:267-93.

8 Billing B, Dahlqvist R, Hornblad Y, Leideman T, Sk $\vec{\sigma}$ reke $\mathrm{L}$, Ripe $\mathrm{E}$. Theophylline in maintenance trea $\mathrm{B}$ ment of chronic asthma: concentration-dependen additional effect to $\mathrm{B}_{2}$ agonist therapy. Eur $J$ Resp Dis 1987;70:35-43.

9 Jackson SHD, Shah K, Debbas NMG, Johnston AQ⿳⺈ Peverel-Cooper CA, Turner P. The interactio between iv theophylline and chronic oral dosing witb slow release nifedipine in volunteers. $\mathrm{Br} \mathrm{J}$ Clin Phase macol 1986;21:389-92.

10 Seely J. Nifedipine increases and glyceryl trinitrate decreases apparent liver blood flow in normal subjects. Br J Clin Pharmacol 1984;17:83-5.

11 Jack DB. Factors contributing to variability in drus pharmacokinetics. 3. Metabolism. J Clin Hosp Phar macy 1985;10:25-43. 